\title{
Effect of Cane on the Knee and Thorax Biomechanics in the Early Postoperative Period Following Total Knee Arthroplasty
}

\author{
Hidenori Tanikawa*1, Ryo Ogawa ${ }^{2}$, Kengo Harato ${ }^{2}$, Yasuo $\mathrm{Niki}^{2}$, Shu Kobayashi ${ }^{2}$, Kazunari Okuma ${ }^{3}$, \\ Takeo Nagura ${ }^{4}$
}

${ }^{1}$ Department of Orthopaedic Surgery, Saiseikai Yokohamashi Tobu Hospital, japan

${ }^{2}$ Department of Orthopaedic Surgery, Keio University School of Medicine, Japan

${ }^{3}$ Department of Orthopaedic Surgery, Saitama City Hospital, Japan

${ }^{4}$ Department of Clinical Biomechanics, Keio University School of Medicine, Japan

Received: April 10, 2018; Published: April 16, 2018

*Corresponding author: Hidenori Tanikawa, Department of Orthopaedic Surgery, SaiseikaiYokohamashi Tobu Hospital, 3-6-1 Shimosueyoshi, Tsurumi, Yokohama, Kanagawa, Japan, Tel: 81455763000; Fax: 81455763525; Email: adriatic123sea@gmail.com

Abstract

Background: Although total knee arthroplasty (TKA) reliably reduces pain and improves knee function, several months are needed for the damaged quadriceps muscles to recover to preoperative strength. Patients with weak muscle strength often use a walking aid to prevent from falling after TKA. The aim of this study is to investigate the biomechanical effect of contralateral cane use on the knee and trunk movement in patients after TKA.

Methods: Twenty people with knee osteoarthritis scheduled to undergo unilateral TKA were enrolled in the study. The movements of knee joint and trunk were measured using three-dimensional motion analysis during walking. The kinematic and kinetic variables were statistically compared between aided walking and unaided walking using two-tailed paired t-tests.

Results: The peak knee adduction moment was significantly smaller in aided walking than in unaided walking. The peak trunk flexion angle and the peak trunk angle to the non-operated side were significantly smaller in aided walking than in unaided walking. The amount of coronal displacement of trunk in aided walking was significantly smaller than the unaided walking.

Conclusion: The use of a cane during walking decreases GRF by $5.6 \%$ and knee adduction moment by $15.8 \%$. Also, the amount of coronal displacement of the trunk decreased with the use of a cane. Using a cane for walking during the initial rehabilitation period after TKA decrease the load on the knee joint, stabilize the movement of the trunk, and may useful for preventing patients from falls.

Keywords: Gait Analysis; Total Knee Arthroplasty; Biomechanics; Trunk; Cane

Abbreviations: TKA: Total Knee Arthroplasty; OA: Osteoarthritis; GRF: Ground Reaction Force

\section{Introduction}

Knee osteoarthritis (OA) is one of the leading causes of disability among elderly people over 65 years old. The incidence of knee $\mathrm{OA}$ increases with age and is characterized by joint instability, muscle weakness, joint deformity, pain and stiffness [1-3]. Total knee arthroplasty (TKA) is a common surgery for the management of severe pain in knee OA. TKA is a surgical intervention that eliminates pain and knee deformity and improves patient quality of life. Furthermore, TKA not only reduces pain in knee OA patients, but improves gait performance and balance function [4,5]. Elderly patients who have undergone TKA have been found to have some increased risk of falls. Older adults who undergo joint replacement surgery may have reduced proprioception, as well as a short-term increase in pain and reduction in muscle strength following surgery [6-8]. These deficits as well as the hospital admission itself may affect older adults who have less physical reserve and ability to compensate for these deficits than younger adults. Previous studies conducted with TKA patients have presented postoperative fall rate starting from $22 \%$ up to $40 \%$ [9-12].

According to the literature the intrinsic risk factors responsible for $39 \%-53 \%$ to falls in the elderly people are history of falls [12- 
$14]$, advanced age $[15,16]$, gender $[15,16]$, muscle weakness [17], reduced physical activity [17], mobility disorders and abnormal gait [18], and fear of falling $[12,13,19]$. Although TKA reliably reduces pain and improves knee function, several months are needed for the damaged quadriceps muscles to recover to preoperative strength. Quadriceps muscle weakness is most pronounced during the first month after surgery, and patients with weak muscle strength often use a walking aid to prevent from falling [20]. Previous biomechanical studies have found that patients frequently exhibit changes in gait biomechanics after TKA [21-25]. Patients after TKA exhibited a quadriceps avoidance gait pattern as the quadriceps muscles contribute less to the knee extension moment. A previous biomechanical study has revealed that, although there was a significant decrease in the contribution of the quadriceps muscles to the vertical acceleration and forward deceleration of the center of mass during walking, the patients with TKA compensated for this deficiency by leaning their trunks forward [21].

Furthermore the control of trunk movement was found to be critical to maintain balance and prevent falls [22-25]. The trunk constitutes two-thirds of the body weight; even slightly uncoordinated movement of the trunk may increase the risk of balance loss and falls after TKA. Until now, few studies have been performed on the variation of knee and trunk movement in TKA patients using a three-dimensional gait analysis system. The aim of this study is to investigate the biomechanical effect of cane use on the knee and trunk movement in patients after TKA. Our hypothesis was that using a cane in the early postoperative period following TKA affects the knee and trunk biomechanics in the way of decreasing knee joint load and increasing trunk balance during walking.

\section{Materials and Methods}

\section{Subjects}

Twenty female patients with knee osteoarthritis (OA) (mean (SD) age, 72.9 (5.2) years; height, 1.51 (0.059) m: mass, 57.6 $(8.68 \mathrm{~kg})$ scheduled to undergo unilateral TKA were enrolled in the study. Patients who underwent hip joint arthroplasty or high tibial osteotomy, were diagnosed as rheumatoid arthritis, or could not walk without an assistive device, were excluded. The surgery was performed by a single surgeon using a standard medial trivector approach. A posterior stabilized type implant (Triathlon, Stryker, and Kalamazoo, MI) was used in all cases. All study protocols were approved by the Institutional Review Board of our institution, and informed consent was obtained from each patient prior to initiation of the study.

\section{Gait Analysis}

The measurements of patients were performed using eight optoelectronic cameras (Pro-reflex, Qualities) and four force plates (AM6110, Bertec) at synchronized frequencies of $120 \mathrm{~Hz}$. Threedimensional motion analysis was carried out using twenty-seven reflective markers placed on each segment of the lower extremities, pelvis, and trunk [26] The details of marker placement are showed in (Figure 1). Measurements were performed at three weeks after surgery, and the length of a cane was fit to each patient by one physiotherapist. Patients were instructed to walk with and without a cane at a comfortable self-selected speed. After a few practice trials, eight trials were recorded for each task, and successful trials with a clear hit on the force plate were selected for analysis. The analysis area was defined as from heel-touch to toe-off of each leg. Visual 3D software (C-Motion, Inc.) was used to calculate knee and trunk joint kinematics and kinetics in sagittal and frontal planes. All kinetic data were normalized to body mass. The variables, including peak ground reaction force (GRF), peak knee flexion angle, peak knee moments (flexion, extension, and adduction), peak trunk angle relative to the pelvis (flexion, extension, the operated side, and the non-operated side), and the amount of coronal displacement of the trunk were statistically compared between aided walking and unaided walking.

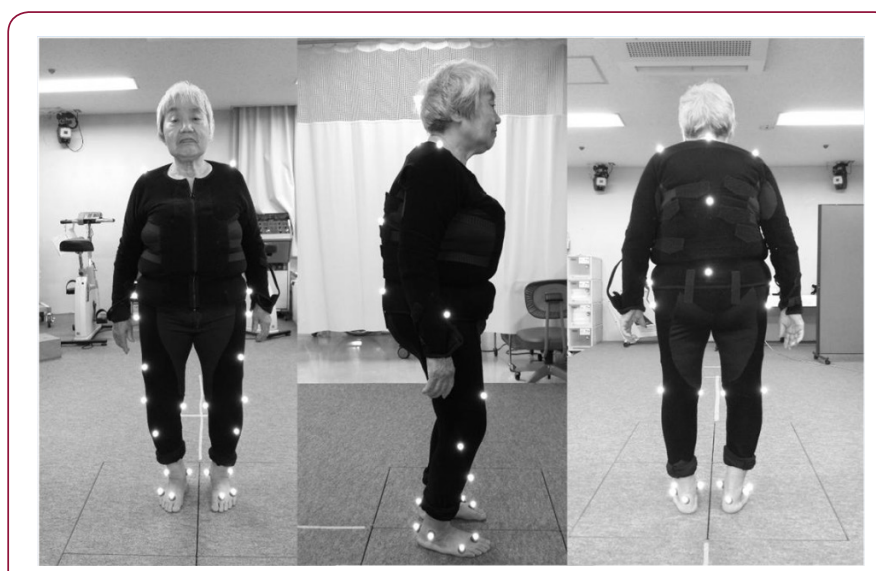

Figure 1: Twenty-seven retro reflective markers were placed on acromion, 7 th cervical vertebla, 10th thoracic vertebla, 5th lumber vertebla, iliac crest, greater trochanter, thigh, medial and lateral epichondyles of a knee, shank, medial and lateral malleoli of an ankle, heads of 1st and 5 th metatarsal bones, and calcaneus.

\section{Statistical Analysis}

Statistical differences in gait parameters (ground reaction force, average velocity of the center of pelvis, knee flexion angle, knee flexion, extension, and adduction moments, trunk flexion and extension angle, trunk angle to the operated side and to the non-operated side, and the amount of coronal displacement of the thorax) between aided walking and unaided walking were evaluated by two-tailed paired t-tests. Statistical analyses were performed using PASW software version 17.0 (SPSS Inc., Chicago, IL). The level of significance was set at $\mathrm{P}=0.05$.

\section{Results}

Kinematics and kinetics data of the knee joint and trunk are shown in (Table 1) and (Figure 2). There was no significant difference in the peak knee flexion angle, the peak knee flexion moment, and the peak knee extension moment between the aided and unaided walking, while the peak knee adduction moment was smaller in aided walking (Table 1). With respect to the biomechanics of the trunk movement, the peak flexion angle and the peak angle to the non-operated side were significantly smaller in aided 
walking than in unaided walking, while the peak extension angle and the peak angle to the operated side was significantly larger in unaided walking (Table 1) and (Figure 2). The amount of coronal displacement of the trunk in aided walking was significantly smaller than in unaided walking (Table 1). The peak GRF normalized to body mass (mean (SD), 0.84 (0.07) in aided walking, $0.89(0.07)$ in unaided walking) and average velocity of the center of pelvis (mean (SD), $0.67(0.15) \mathrm{m} / \mathrm{s}$ in aided walking, $0.71(0.16) \mathrm{m} / \mathrm{s}$ in unaided walking) were significantly smaller in aided walking than unaided walking $(\mathrm{P}<0.05)$.

Table 1: Mean (SD) values of the kinetics and kinematics of the knee joint and trunk.

\begin{tabular}{|c|c|c|c|c|}
\hline Variables & Aided & Unaided & $\begin{array}{c}\text { Mean } \\
\text { difference } \\
\mathbf{9 5 \% ( I )}\end{array}$ & $\mathbf{P}$ \\
\hline $\begin{array}{c}\text { Knee flexion angle } \\
\text { (degrees) }\end{array}$ & $16.9(6.0)$ & $17.4(6.4)$ & $\begin{array}{c}-0.36(-1.34, \\
0.62)\end{array}$ & 0.45 \\
\hline $\begin{array}{c}\text { Knee flexion } \\
\text { moment (Nm/kg) }\end{array}$ & $0.23(0.13)$ & $0.25(0.11)$ & $\begin{array}{c}-0.03(-0.07, \\
0.02)\end{array}$ & 0.99 \\
\hline $\begin{array}{c}\text { Knee extension } \\
\text { moment (Nm/kg) }\end{array}$ & $0.25(0.10)$ & $0.25(0.13)$ & $\begin{array}{c}0.00(-0.45, \\
0.45)\end{array}$ & 0.21 \\
\hline $\begin{array}{c}\text { Knee adduction } \\
\text { moment (Nm/kg) }\end{array}$ & $0.32(0.11)$ & $0.38(0.12)$ & $\begin{array}{c}-0.06(-0.08, \\
-0.03)\end{array}$ & $<0.001$ \\
\hline $\begin{array}{c}\text { Trunk flexion } \\
\text { angle (degrees) }\end{array}$ & $2.85(8.15)$ & $3.86(7.94)$ & $\begin{array}{c}-1.01(-1.55 \\
-0.48)\end{array}$ & $<0.001$ \\
\hline $\begin{array}{c}\text { Trunk extension } \\
\text { angle (degrees) }\end{array}$ & $-0.26(8.02)$ & $-1.06(7.80)$ & $\begin{array}{c}0.80(0.34, \\
1.26)\end{array}$ & 0.002 \\
\hline $\begin{array}{c}\text { Trunk angle to } \\
\text { the operated side } \\
\text { (degrees) }\end{array}$ & $3.74(3.11)$ & $2.65(2.98)$ & $\begin{array}{c}1.08(0.40, \\
1.77)\end{array}$ & 0.004 \\
\hline $\begin{array}{c}\text { Trunk angle to the } \\
\text { non-operated side } \\
\text { (degrees) }\end{array}$ & $0.77(3.88)$ & $2.08(3.61)$ & $\begin{array}{c}-1.31(-2.11, \\
-0.51)\end{array}$ & 0.003 \\
\hline $\begin{array}{c}\text { Amount of } \\
\text { coronal }\end{array}$ & $4.62(1.35)$ & $5.26(1.29)$ & $\begin{array}{c}-0.63(-1.26, \\
0.00)\end{array}$ & 0.005 \\
$\begin{array}{c}\text { displacement of } \\
\text { the trunk (cm) }\end{array}$ & & & & \\
\hline
\end{tabular}

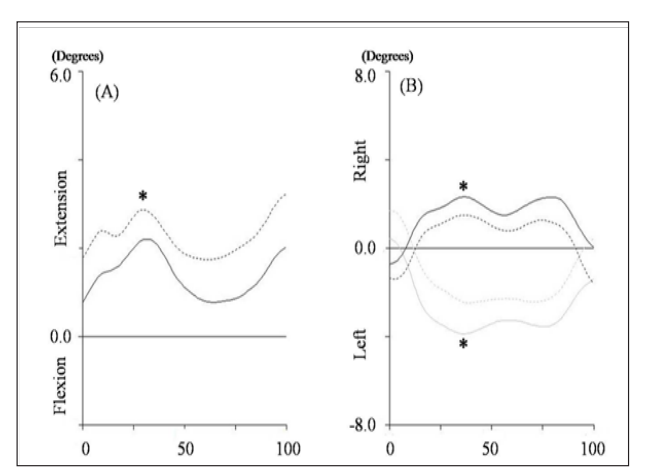

Figure 2: Trunk angle relative to the pelvis in sagittal plane (A) and coronal plane (B) are shown. Solid and dot lines indicate the aided and unaided walking, respectively. In the graph of the coronal plane (B), black and gray lines indicate the data of the patients who underwent TKA in his or her right and left knee, respectively.

*indicates significant difference $(\mathrm{P}<0.05)$.

\section{Discussion}

This is the first study that evaluated the biomechanical alteration in knee and trunk movement between aided walking and unaided waking after TKA. Using a cane during walking at the early postoperative period after TKA alters the kinematics and kinetics of knee joint and trunk. The use of a cane during walking decreases GRF by $5.6 \%$ and knee adduction moment by $15.8 \%$. Our result is similar to previous studies that evaluated the effect of a cane in people with knee $\mathrm{OA}$, which showed that the use of a cane decreased knee load by $10 \%$ when using a cane in the contra lateral hand [27] Past reports documented that the strength of quadriceps and hamstring muscles declines to $50 \%$ of the preoperative level in the first four weeks after surgery [20]. Using a cane during the initial rehabilitation period may decrease the load on the operated knee and may be useful to avoid excess stress on the surgically invaded muscles. In regard with knee adduction moment, the use of a cane after TKA decreases knee adduction moment by $15.8 \%$, which is in agreement with past gait studies following TKA which reported a peak knee adduction moment of between 2.5 and $3.0 \%$ $(\mathrm{BW} \times \mathrm{Ht})$ [28-31].

In the current study, the thorax tends to tilt to the operated side relative to the pelvis during aided walking, resulting in a shift of the gravity center to the operated side, which may cause decrease of the knee adduction moment during aided walking. External knee adduction moment during gait is known to be a key variable in understanding frontal knee mechanics. Although, the clinical significance of a high knee adduction moment following TKA remains unclear, it has been proposed that there is a positive relationship between high knee flexion moment during gait and tibial component loosening [32]. Furthermore, a systematic review states a possible relationship between polyethylene wear in the medial tibia insert and postoperative knee adduction moment [33], but there is currently no study which clearly shows a direct relationship between greater knee adduction moment and mechanical failure following TKA.

Until now, few studies have been performed on the variation of trunk movement in knee OA patients pre- or post-TKA using a three-dimensional gait analysis system. The current study found that trunk tends to extend and tilt to the operated side relative to the pelvis with the use of a cane. Additionally, the amount of coronal displacement was decreased with the use of a cane, suggesting that thorax movement may be stabilized during walking. Our results are supported by the previous literature examining the alternation of trunk movement in patients with TKA, documenting that the maximal trunk speed to the non-arthroplasty side and the maximal trunk displacement to the arthroplasty side were both reduced in a medio-lateral direction after TKA [24]. As OA patients show weak muscle strength on the arthroplasty side, the reduction of trunk movement to the arthroplasty side with a cane has a beneficial effect on maintaining body balance and reducing falls. In regards with the sagittal plane of trunk movement, a previous biomechanical study has revealed that patients with TKA compensated for the deficiency of quadriceps muscles by leaning their trunks forward [21]. 
Another previous study has found the strong correlation between patients with kyphosis and falls after TKA [34]. It has been proposed that the trunk flexion has a biomechanical significance in that it may lead to falls [35], the use of a cane in the early period following TKA may be beneficial to prevent falls as it extend the trunk during walking. Our study has several limitations that need to be considered. Firstly, the study lacks a long-term follow-up. Functional recovery of the lower extremities and trunk movement after TKA is a long-term process, affected by many factors. Secondly, patients with unilateral knee OA may have some degenerative changes and slight pain at other joints of the lower extremities, and these may be factors limiting our results. Thirdly the small sample size could also affect the results.

\section{Conclusion}

Using a cane for walking during the early postoperative period following TKA alters the kinematics and kinetics of the knee and trunk, may decrease the load on knee joint, and stabilize the movement of trunk.

\section{Acknowledgement}

The authors thank to Mr. Tomonori Muto, Ms. Hiroko Arai, and Ms. Hiroko Tanikawa for their assistance to take care of the patients.

\section{References}

1. Fisher NM, Pendergast DR (1997) Reduced muscle function in patients with osteoarthritis. Scand J Rehabil Med 29(4): 213-221.

2. Jadelis K, Miller ME, Ettinger WH Jr, Messier SP (2001) Strength, balance, and the modifying effects of obesity and knee pain: results from the Observational Arthritis Study in Seniors (oasis). J Am Geriatr Soc. 49(7): 884-891.

3. Martin JA, Buckwalter JA (2002) Aging, articular cartilage chondrocyte senescence and osteoarthritis. Biogerontology 3(5): 257-264.

4. Bade MJ, Kohrt WM, Stevens Lapsley JE (2010) Outcomes before and after total knee arthroplasty compared to healthy adults. J Orthop Sports Phys Ther 40(9): 559-567.

5. Cho SD, Hwang CH (2013) Improved single-limb balance after total knee arthroplasty. Knee Surg Sports TraumatolArthrosc 21(12): 2744-2750.

6. Rasch A, Dalen N, Berg HE (2010) Muscle strength, gait, and balance in 20 patients with hip osteoarthritis followed for 2 years after THA ActaOrthop 81(2): 183-188.

7. Pozzi F, Snyder Mackler L, Zeni J (2013) Physical exercise after knee arthroplasty: a systematic review of controlled trials. Eur J Phys Rehabil Med 49(6): 877-892.

8. Levinger P, Menz HB, Morrow AD, Wee E, Feller JA, et al. (2012) Lower limb proprioception deficits persist following knee replacement surgery despite improvements in knee extension strength. Knee Surg Sports TraumatolArthrosc 20(6): 1097-1103.

9. Swinkels A, Newman JH, Allain TJ (2009) A prospective observational study of falling before and after knee replacement surgery. Age Ageing 38(2): 175-181.

10. Matsumoto H, Okuno M, Nakamura T, Yamamoto K, Hagino H (2012) Fall incidence and risk factors in patients after total knee arthroplasty. Arch Orthop Trauma Surg 132(4): 555-563.

11. Levinger P, Wee E, Margelis S, Menz HB, Bartlett JR, et al. (2017) Preoperative predictors of post-operative falls in people undergoing total hip and knee replacement surgery: a prospective study. Arch Orthop Trauma Surg 137(8): 1025-1033.
12. Tsonga T, Michalopoulou M, Kapetanakis S, Giovannopoulou E, Malliou P, et al. (2016) Reduction of Falls and Factors Affecting Falls a Year After Total Knee Arthroplasty in Elderly Patients with Severe Knee Osteoarthritis. Open Orthop J 10: 522-531.

13. Tinetti ME, Speechley M, Ginter SF (1988) Risk factors for falls among elderly persons living in the community. N Engl J Med 319(26):17011707.

14. Nevitt MC, Cummings SR, Hudes ES (1991) Risk factors for injurious falls: a prospective study. J Gerontol 46(5): M164-170.

15. Campbell AJ, Spears GF, Borrie MJ (1990) Examination by logistic regression modelling of the variables which increase the relative risk of elderly women falling compared to elderly men. J ClinEpidemiol 43(12): 1415-1420.

16. Robbins AS, Rubenstein LZ, Josephson KR, Schulman BL, Osterweil D, et al. (1989) Predictors of falls among elderly people. Results of two population-based studies. Arch Intern Med 149(7): 1628-1633.

17. (2001) American Academy of Orthopedic Surgeons panel of falls prevention. Guideline for the prevention of falls in older persons. J Am GeriatrSoc 49(5): 664-672.

18. Maki BE, McIlroy WE (1996) Postural control in the older adult. Clin Geriatr Med 12(4): 635-658.

19. Friedman SM, Munoz B, West SK, Rubin GS, Fried LP (2002) Falls and fear of falling: which comes first? A longitudinal prediction model suggests strategies for primary and secondary prevention. J Am GeriatrSoc 50(8): 1329-1335.

20. Kemp G, Crossley KM, Wrigley TV, Metcalf BR, Hinman RS (2008) Reducing joint loading in medial knee osteoarthritis: shoes and canes. Arthritis Rheum 59(5): 609-614.

21. Li K, Ackland DC, Mc Clelland JA, Webster KE, Feller JA, et al. (2013) Trunk muscle action compensates for reduced quadriceps force during walking after total knee arthroplasty. Gait Posture 38(1): 79-85.

22. Berman AT, Quinn RH, Zarro VJ (1991) Quantitative gait analysis in unilateral and bilateral total hip replacements. Arch Phys Med Rehabil 72(3): 190-194.

23. Shakoor N, Block JA, Shott S, Case JP (2002) Nonrandom evolution of end-stage osteoarthritis of the lower limbs. Arthritis Rheum 46(12): 3185-3189.

24. Chang QZ, Sohmiya M, Wada N, Tazawa M, Sato N, et al. (2011) Alternation of trunk movement after arthroplasty in patients with osteoarthritis of the knee. J Orthop Sci 16(4): 382-388.

25. Niki Y, Nagura T, Nagai K, Kobayashi S, Harato K (2017) Kinematically aligned total knee arthroplasty reduces knee adduction moment more than mechanically aligned total knee arthroplasty. Knee Surg Sports Traumatol Arthrosc.

26. Molina Rueda F, Alguacil Diego IM, Cuesta Gómez A, Iglesias Giménez J, Martín Vivaldi A, et al. (2014) Thorax, pelvis and hip pattern in the frontal plane during walking in unilateral transtibial amputees: biomechanical analysis. Braz J Phys Ther 18(3): 252-258.

27. Chan GN, Smith AW, Kirtley C, Tsang WW (2005) Changes in knee moments with contralateral versus ipsilateral cane usage in females with knee osteoarthritis. Clin Biomech (Bristol, Avon) 20(4): 396-404.

28. Alnahdi AH, Zeni JA, Snyder Mackler L (2011) Gait after unilateral total knee arthroplasty: frontal plane analysis. J Orthop Res 29(5): 647-652.

29. Hatfield GL, Hubley Kozey CL, Astephen Wilson JL, Dunbar MJ (2011) The effect of total knee arthroplasty on knee joint kinematics and kinetics during gait. J Arthroplasty 26(2): 309-317.

30. Mandeville D, Osternig LR, Lantz BA, Mohler CG, Chou LS (2008) The effect of total knee replacement on the knee varus angle and moment during walking and stair ascent. Clin Biomech 23(8): 1053-1058. 
31. Orishimo KF, Kremenic IJ, Deshmukh AJ, Nicholas SJ, Rodlriguez JA (2012) Does total knee arthroplasty change frontal plane knee biomechanics during gait? Clin Orthop Relat Res 470(4): 1171-1176.

32. Hilding MB, Lanshammar H, Ryd L (1996) Knee joint loading and tibial component loosening. RSA and gait analysis in 45 osteoarthritic patients before and after TKA. J Bone Joint Surg Br 78(1): 66-73.

33. Komnik I, Weiss S, Fantini Pagani CH, Potthast W (2015) Motion analysis of patients after knee arthroplasty during activities of daily living-a systematic review. Gait Posture 41(2): 370-377.

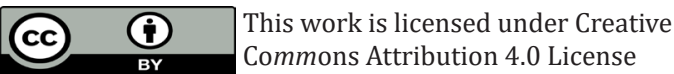

Submission Link: https://biomedres.us/submit-manuscript.php
34. Matsumoto $H$, Okuno M, Nakamura T, Yamamoto $K$, Osaki $M$, et al. (2014) Incidence and risk factors for falling in patients after total knee arthroplasty compared to healthy elderly individuals. Yonago Acta Med 57(4): 137-145.

35. Grabiner MD, Donovan S, Bareither ML, Marone JR, Hamstra Wright K, et al. (2008) Trunk kinematics and fall risk of older adults: translating biomechanical results to the clinic. J Electromyogr Kinesiol 18(2): 197204.

\begin{tabular}{ll} 
BIOMEDICAL & Assets of Publishing with us \\
RESEARCHES & - Global archiving of articles \\
\hline ISSN:2574-1241 & - Immediate, unrestricted online access \\
\hline
\end{tabular}

